\title{
Corrigendum: Serial, Anthropomorphic, Spatial, Mechatronic Systems can be Studied More Simply in a Plan
}

\author{
${ }^{1}$ Relly Victoria Virgil Petrescu, ${ }^{2}$ Raffaella Aversa, ${ }^{2}$ Antonio Apicella, ${ }^{3}$ Samuel Kozaitis, ${ }^{4}$ Taher Abu-Lebdeh \\ and ${ }^{1}$ Florian Ion Tiberiu Petrescu
}

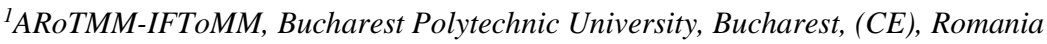

${ }^{2}$ Advanced Material Lab, Department of Architecture and Industrial Design,

Second University of Naples, 81031 Aversa (CE), Italy

${ }^{3}$ Florida Institute of Technology, USA

${ }^{4}$ North Carolina A and T State University, USA

\begin{abstract}
Correction to: Journal of Mechatronics and Robotics
http://doi.org/10.3844/jmrsp.2017.88.97, published online 20 December 2017;

updated 29 April 2019
\end{abstract}

The original version of this Article contained Mr. MirMilad Mirsayar as a Co-

Author. Mr. Mirsayar has not contributed to the preparation and publication of this manuscript.

These errors have now been corrected in the HTML and PDF versions of the Article.

http://doi.org/10.3844/jmrsp.2017.88.97. 